\title{
Porfirio Díaz en la historiografía masónica mexicana $^{1}$
}

\author{
Marco Antonio Flores Zavala \\ Profesor-investigador en la Unidad Académica de Historia de la Universidad Autónoma de Zacatecas, \\ México. Correo electrónico: marcoflo@yahoo.com
}

DOI: http://dx.doi.org/10.15517/rehmlac.v7i2.22694

Fecha de recibido: 7 de agosto de 2015 - Fecha de aceptación: 4 de septiembre de 2015

\author{
Palabras claves \\ Biografías, historiografía, representación, antropología política, régimen, sistema políticos
}

Keywords

Biographies, historiography, representation, political anthropology, regime, political system

\begin{abstract}
Resumen
En este artículo se analiza la presencia del general Porfirio Díaz en la historiografía masónica mexicana. Para la redacción de este texto se recurrió a las obras de José María Mateos (Historia de la masonería en México desde 1806 hasta 1884), Richard Chism (Una contribución a la historia masónica de México) y Luis J. Zalce (Apuntes para la historia de la masonería en México, de mis lecturas y mis recuerdos). El cuestionario es básico: ¿Qué fuentes documentales utilizaron los autores para redactar sus textos? ¿Cómo examinan la actuación del general Díaz, como actor de un régimen o un hermano masón? Pese a lo elemental de las preguntas, éstas colaboran para situar parte de los tópicos y de las formas en que fueron redactadas las historias de la masonería en México. El artículo está integrado con dos secciones. En la primera se esboza una biografía del general Díaz y se presentan las obras que se definen como historiografía masónica mexicana. La segunda sección presenta la descripción de las obras y cómo examinaron la presencia de Díaz en la masonería.
\end{abstract}

\begin{abstract}
This article analyses the presence of General Porfirio Diaz in Mexican Masonic historiography, using the works of José María Mateos (History of Freemasonry in Mexico from 1806 to 1884), Richard Chism (A contribution to the Masonic history of Mexico) and Luis J. Zalce (Notes on the history of Freemasonry in Mexico, my reading and my memories). The line of questioning is basic: What documentary sources were used by the authors to write their texts? How did they examine the performance of General Diaz, as an actor of the regime or a brother Mason? Although these are elemental questions, together they elucidate the ways in which Freemasonry was written about in Mexico. The article comprises two sections: The first outlines a biography of General Diaz and the works that are defined as Mexican Masonic historiography are presented. The second section presents a description of the work and how it examined the presence of Diaz in Freemasonry.
\end{abstract}

\footnotetext{
${ }^{1}$ Parte de la información de este artículo es parte de la tesis doctoral "Masones y masonería en México, 17601934” que será leída en la Universitat Jaume I, bajo la dirección del doctor Manuel Chust Calero.
} 


\section{Generalidades}

El general Porfirio Díaz Mori fue presidente de la República mexicana (1876-1880 y 1884-1911). El período durante el cual gobernó se le ha denominado como el Porfiriato. Éste, con lo que conlleva: la biografía del militar y la de los políticos que gobernaron entonces; la cultura política; las instituciones de un Estado federal; los modos de gobernar; las formas de hacer sociedad; las rupturas y continuidades -en relación a la Revolución mexicana-; las particularidades de las regiones; éstas, entre otros temas, no son un asunto inédito en la historiografía mexicana, tampoco lo es para los investigadores extranjeros que estudian los complejos procesos de construcción de los Estado-nación en Latinoamérica ${ }^{2}$. Si bien el Porfiriato es una línea de investigación permanente, en años recientes volvió a la discusión pública (en la academia y en la opinión pública) ${ }^{3}$. El retorno fue una correspondencia a los centenarios de la Revolución mexicana (noviembre de 2010) y el aniversario del fallecimiento del militar (mayo de 2015).

Una parte de la historiografía que ronda al general Díaz, el período, el Estado, el régimen y el sistema políticos, tiene presente a la masonería como un tópico que ayuda a explicar las redes sociales y la cultura política mexicana. Paul Garner asentó:

En la política mexicana del siglo XIX, la masonería aportó un enlace crucial entre la política liberal y la construcción de redes políticas o facciones que giraban en torno al liderazgo de individuos particulares. Los politólogos han identificado estas redes o grupos informales personalistas, o sea las camarillas, como una de las características principales de la cultura política mexicana del siglo XX. Su importancia para el siglo XIX ha sido reconocida en menor grado, pero no era menos crucial ${ }^{4}$.

La inclusión de la masonería en la historiografía se debe a la participación de importantes actores políticos de la Ciudad de México, de las capitales estatales, y de ignorados políticos de tierra adentro. En lo que corresponde al general Díaz, algunas biografías indican que fue iniciado en una logia de Oaxaca. Carlos Tello Díaz escribió:

En 1852 el Instituto era más laico, más independiente, más propuesto a recibir en sus aulas los tránsfugas del Seminario, a quienes orientaba en una dirección que para muchos era contraria a las enseñanzas de la Iglesia. Pues sus profesores, liberales en su mayoría, eran con frecuencia, además, masones. También sus

\footnotetext{
${ }^{2}$ Para un panorama historiográfico del Porfiriato ayuda el compendio de Mauricio Tenorio Trillo y Aurora Gómez Galvarrio, El Porfiriato (México, D.F.: CIDE, FCE, 2013).

${ }^{3}$ Como referencia está la revista Nexos [México, director Héctor Aguilar Camín]. En el número de julio de 2015 presentó un dossier sobre el general Díaz, lo hizo con la siguiente entrada "Hay una zona prohibida de la historia de México. Esa zona se llama Porfirio Díaz. A la vez es una de las más visitadas por los historiadores y la memoria popular. ¿Qué hay en esa zona?”. Escribieron Jean Meyer, Claudio Lomnitz, Fernando Escalante, Mauricio Tenorio, José Antonio Aguilar Rivera, Paul Garner, Alan Knigth, Carlos Tello Díaz.

${ }^{4}$ Paul Garner, Porfirio Díaz. Del héroe al dictador, una biografia política (México D.F.: Planeta, 2003), 39.
} 
estudiantes. El tercianista Porfirio Díaz, en concreto, fue iniciado por aquellas fechas -unos dicen que ese año, el " 2 de abril"- en los secretos de la masonería. Al parecer fue presentado por Marcos Pérez, quien era venerable maestro de la Logia Cristo de Oaxaca. Esa logia pertenecía al Rito Nacional Mexicano, el único que existía desde el declive de los escoceses y yorkinos en toda la República. Durante las reuniones con sus hermanos de la Logia Cristo, Porfirio descubrió, acaso con sorpresa, a muchos de sus más respetados profesores en el Instituto, como Benito Juárez y Cenobio Márquez, y también a varios de sus condiscípulos, entre ellos Francisco Vasconcelos ${ }^{5}$.

La biografía masónica de Porfirio Díaz da cuenta de un masón activo. La posesión de los máximos grados en los ritos Nacional Mexicano (RNM) y Escocés Antiguo y Aceptado (REAyA) le permitieron participar en logias asentadas en la Ciudad de México e intervenir en talleres del interior del país. En la interacción con masones, logias y grandes logias, Díaz fue admitido y tuvo reconocimiento como un dirigente de la amplia y compleja red de relaciones sociales masónicas ${ }^{6}$.

En este artículo revisamos la presencia del general Porfirio Díaz en la historiografía masónica mexicana. Para la redacción de este texto recurrimos a las obras de José María Mateos (Historia de la masonería en México desde 1806 hasta 1884), Richard Chism (Una contribución a la historia masónica de México) y Luis J. Zalce (Apuntes para la historia de la masonería en México, de mis lecturas y mis recuerdos) ${ }^{7}$. El cuestionario es básico: ¿Cómo examinan la actuación del general Díaz, cómo actor de un régimen o cómo un hermano masón? ¿Qué fuentes documentales utilizaron los autores para redactar sus textos? Pese a lo elemental de las preguntas, éstas colaboran para situar parte de los tópicos y las formas en que fueron redactadas las historias de la masonería en México.

\section{Un panorama de la masonería durante el Porfiriato}

La comprensión de la masonería como una asociación política contribuyó para que aparecieran movimientos masónicos que mostraban un alto nivel de ignorancia de las normas sobre la actividad ritual. Esta situación contribuyó para integrar grupos que disputaban

\footnotetext{
${ }^{5}$ Tello Díaz recurrió a Porfirio Díaz: el origen [Enrique Krauze y Fausto Zerón-Medina, México, Clío, 1993] y a una entrevista a un dirigente masón del estado de Oaxaca. Señala que no existe documentación sobre la iniciación. Carlos Tello Díaz, Porfirio Díaz. Su vida y su tiempo. La guerra, 1830-1867 (México D.F.: Conaculta, Debate, 2015), 113-114, 488.

${ }^{6}$ El Boletín del Supremo Consejo del grado 33, de 1890, da cuenta que el general Díaz lo titulaban Soberano Gran Comendador ad-vitam. Boletín del Supremo Cons.: del 33... (México D. F.: Tipografía de Ignacio Pombo, 1890).

${ }^{7}$ José María Mateos, Historia de la masonería en México desde 1806 hasta 1884 (México D. F.: Imp. de La Tolerancia, 1884). Richard P. Chism, Una contribución a la historia masónica de México (México D. F.: Imprenta del Minero, 1899). Luis J. Zalce, Apuntes para la historia de la masonería en México, de mis lecturas y mis recuerdos (México D. F.: Ed. del autor, dos tomos, 1950).
} 
espacios en los centros de decisiones interna y externas a la masonería. En este periodo se formaron los ritos Escocés Antiguo y Reformado (1869-1876) ${ }^{8}$; el Escocés Antiguo y Aceptado de Masones Libres e Independientes (1878-1890) ${ }^{9}$; y el Escocés Antiguo Reformado (1892-1900) ${ }^{10}$ y se reinstaló el RNM. Se agrega a esta situación la autonomía de las logias, que no tenían restricciones, en parte por la situación política del país y también por el desconocimiento que tenían de su normatividad. En este contexto la creación de la Gran Dieta Simbólica de los Estados Unidos Mexicanos (1890) sirvió para intentar controlar la masonería del país, con el aliciente de contar con el reconocimiento tácito del presidente Porfirio Díaz.

El triunfo de los liberales republicano sobre la segunda monarquía (1867) permitió que las logias sobrevivientes de los RNM y REAyA continuaran como una de las vías privilegiadas para vincularse y participar en la política, más cuando los principales militares y líderes republicanos eran masones. Entonces las reuniones rituales y conviviales masónicas mantuvieron su atracción para quienes aspiraban a vincularse social y políticamente.

El RNM, hacia 1879, mantenía sus actividades rituales en todos sus grados, las grandes logias realizaban con regularidad sus reuniones en los estados de México, San Luis Potosí, Jalisco, Durango, Hidalgo, Veracruz y Sinaloa. Sin embargo, y a consecuencia de las disidencias que tuvo el REAyA, en la segunda mitad del siglo XIX, en las cuales llegó a intervenir el RNM al otorgar reconocimiento a las nuevas organizaciones, los nacionales disminuyeron sus actividades hasta el grado que su dirigente Francisco de Paula Gochicoa decretó la clausura de sus trabajos y disolvió al rito en 1887. En este hecho no puede ignorarse que masones nacionales se trasladaron a los talleres que impulsaban los escoceses. Una muestra es el mismo Gochicoa, que a finales del siglo pertenecía al Supremo Consejo del REAyA $^{11}$.

Los masones escoceses reinstauraron sus labores a través de la logia Unión Fraternal 20, que obtuvo su Carta patente del Gran Oriente de Nueva Granada y con reconocimiento del Supremo Consejo de la Jurisdicción del Sur de Estados Unidos. Los impulsores del REAyA de esta etapa fueron nuevamente masones extranjeros, el colombiano Pedro Abad del Oro y el

\footnotetext{
${ }^{8}$ Fue una reacción al control ritual que ejerció James C. Loshe. Lo encabezó Juan de Dios Arias, masón del grado 32. Contó con el apoyo y reconocimiento de logias de la Ciudad de México y del estado de Veracruz. Una de sus logias adoptó el rito alemán Ecléctico. Mateos, Historia de la masonería, 167-334.

${ }^{9}$ Lo encabezaron Ermilo G. Cantón e Ignacio M. Altamirano en contra del Supremo Consejo del grado 33. Contó con el apoyo y el reconocimiento de logias de la Ciudad de México, en 1879 contaba con más de cien talleres en el interior del país. La reacción del Supremo Consejo fue la creación de una Gran Logia Central de Libres y Aceptados Masones de los Estados Unidos Mexicanos (1883). Esta disidencia es la génesis de la Gran Dieta Simbólica. Mateos, Historia de la masonería, 323-378. Zalce, Apuntes para la historia, Tomo I, 293-350.

${ }^{10}$ Fue una reacción al control que ejerció Ermilo G. Cantón a través de la Gran Dieta. Lo encabezó Ignacio A. de la Peña. Contó con el apoyo y el reconocimiento de logias de la Ciudad de México y de masones de todos los grados. Zalce, Apuntes para la historia, Tomo I, 335-350.

${ }^{11}$ Zalce, Apuntes para la historia, Tomo I, 379-380. Mateos, Historia de la masonería, 349-378.
} 
norteamericano Santiago Loshe. Por otro lado, en 1860 varios masones republicanos instauraron el Supremo Consejo del REAyA en Veracruz. En abril de 1868 se reunieron los masones que formaban la Gran Logia Valle de México y el Supremo Consejo de Veracruz, para constituir el Supremo Consejo de Grandes Inspectores Generales de grado 33 del REAyA $^{12}$.

Para que el REAyA tuviera un rápido crecimiento y una posterior supremacía sobre las actividades masónicas en México, sus dirigentes atendieron diversas cuestiones: en lo interno, con Loshe a la cabeza, vigilaron el cumplimiento de la normatividad masónica y dieron el primer paso para el control masónico en México. En lo externo, el rito no participó, como tal, en los conflictos políticos, lo que facilitó que algunos masones reconocieran al general Porfirio Díaz como uno de sus líderes ${ }^{13}$.

Provista entonces la masonería un alto grado de libertad para sus integrantes y para sus logias, en el período que abordamos ocurrieron disidencias, cuyos reconocimientos estuvieron determinados por el tipo de relaciones externas y políticas entre los individuos que participaron en los hechos. Por ejemplo, el Rito Escocés Antiguo y Reformado, que se formó bajo la dirección del gobernador del Distrito Federal, tuvo el reconocimiento del RNM -éste no era considerado rito regular por las obediencias masónicas de otros países-. Si bien las disidencias se escenificaban fundamentalmente en la Ciudad de México, las logias del interior de la República tenían diversas reacciones: unas participaban en las controversias y otras se mantenían al margen. Una muestra es la logia escocesa Salomón de Guadalajara, que permaneció fuera de las disputas. Suponemos que una de las razones de su exclusión era la presencia del general Ramón Corona en su seno, pues éste no reconoció las rupturas y aceptó a masones de cualquier rito. Anteriormente el general Corona había fungido como dirigente de la Gran Logia de Occidente de Durango y de la Gran Logia del Estado de Jalisco, ambos del RNM. $^{14}$

Aun cuando algunos masones de los REAyA y RNM participaron en la asonada que permitió el ascenso presidencial del general Porfirio Díaz, no significó que la contienda fuera un conflicto de facciones políticas con trasfondo masónico, como ocurrió con los primeros ritos masónicos de México. No estaba en lucha la concepción política del país por parte de los masones, su interés era por acceder al poder, era una lucha personalista y de redes políticas. Quizá por esto no es extraño que siendo masón el presidente Porfirio Díaz, conocedor del beneficio de las relaciones y de los compromisos en la discreción de las logias, aprovechó la

\footnotetext{
${ }^{12}$ En Veracruz estuvieron presentes Ignacio Comonfort, Porfirio Díaz, Nicolás Pizarro Suárez, José García Conde y Alfredo Chavero. En la Ciudad de México se unieron a Loshe, José Enciso, José González, Juan Martínez y Diego Castillo Moreno. La presencia de estos masones mexicanos, nos permite afirmar la trayectoria del proceso de mexicanización de la masonería. Mateos, Historia de la masonería, 167-247.

13 "Alfredo Chavero a Porfirio Díaz", Cd. de México, abril 26 de 1878, "Ermilo G. Cantón a Porfirio Díaz" Cd. de México, febrero 13 de 1878 y "Sóstenes Rocha a Porfirio Díaz", Cd. de México, febrero 8 de 1890, en Colección Porfirio Díaz, Universidad Iberoamericana (CPD-UI).

${ }^{14}$ Zalce, Apuntes para la historia, Tomo I, 199, 284-289.
} 
coyuntura que le otorgaron algunos masones escoceses -el general Sóstenes Rocha y Ermilo G. Cantón- para instaurar la Gran Dieta Simbólica en México, para controlar e influir en una red paralela a los clubes políticos y las tertulias sociales y culturales que reunía a individuos con poder.

En 1890 la Gran Dieta Simbólica sustituyó al Gran Oriente que formó el Rito Escocés Antiguo y Aceptado de Masones Libres e Independientes. Su función de cuerpo consultivo sobre temas masónicos, tenía por fondo el control de más de ciento cincuenta logias simbólicas dispersas y con una alta posibilidad de "formar pequeñas repúblicas masónicas en cada estado", según Ermilo G. Cantón. La Dieta también afianzó el liderazgo de Díaz al integrarse una relación social cerrada que reconocía su autoridad como gobernante y lo elegía como su gran maestro, ejerciendo una dominación directa sobre la masonería ${ }^{15}$.

A pesar de ser un organismo dirigente de las actividades masónicas en México y con apoyo gubernamental, la Gran Dieta Simbólica no logró del todo su objetivo. Así lo demuestra el diverso crecimiento y la formación de las Grandes Logias de Estado. Hacia 1893, la nomenclatura de la Dieta tenía inscritas las Grandes Logias Valle de México 1, en la capital del país; Miguel Hidalgo 2, en Toluca; El Sol 3, en Jalapa; Estado de Jalisco 4, en Guadalajara; Benito Juárez 5, en Saltillo; Unión Perpetua 6, en Zacatecas; Unión 7, en Monterrey; El Faro 8, en San Cristóbal; Ignacio Ramírez 9, en Tampico; Víctor Hugo 10, en Oaxaca; Vicente Guerrero 11, en Chilpancingo; Cosmos 13, en Paso del Norte; Luz de la Frontera 14, en Nuevo Laredo; Libres y Aceptados Masones 15, en Puebla; El Potosí 16, en San Luis Potosí; y Estado de Tabasco 17, en Villahermosa. El beneficio del dominio y la estrategia de subordinación de la Gran Dieta para con las grandes logias de estado, contribuyó para que varios gobernadores fueran los grandes venerables maestros y se convirtieran en los responsables directos de las actividades masónicas en sus estados ${ }^{16}$.

La Dieta comenzó a debilitarse en 1895, cuando en el marco de las disidencias que provocaron la creación de logias de mujeres y la expulsión de Ignacio de la Peña de la Gran Dieta, se rebelaron varias logias ${ }^{17}$ que se ampararon en una resolución que decretaba la jurisdicción de las grandes logias de estado sobre los grados simbólicos y su responsabilidad del simbolismo en los límites territoriales de su entidad. Otro hecho que también debe

\footnotetext{
${ }^{15}$ Jean Pierre Bastian, Los disidentes, sociedades protestantes y Revolución en México, 1879-1911 (México D.F.: FCE, El Colegio de México, 1989), 196ss.

${ }^{16}$ Hacia 1894, entre los gobernadores dirigentes de las grandes logias de estado se encuentran Aristeo Mercado de Michoacán; Teodoro Dehesa, en Veracruz; José Vicente Villada, en el Estado de México; Carlos Diez Gutiérrez, en San Luis Potosí; Gildardo Gómez, en Colima; Mucio Martínez, en Puebla; Miguel Ahumada, en Chihuahua; Francisco Arce, en Guerrero; Abraham Bandala, en Tabasco; Bernardo Reyes, en Nuevo León; y Jesús Aréchiga, en Zacatecas. "General Bernardo Reyes a Porfirio Díaz", Monterrey, NL, agosto 30 de 1890, en CPD-UIA. Boletín masónico (Ciudad de México, 1893 y 1895). Zalce, Apuntes para la historia, Tomo I, 341-342.

${ }^{17}$ Esas logias fueron Luz de la Frontera 14, de Nuevo Laredo; Hidalgo 2, de Toluca; Libres y Aceptados 15, de Puebla; El Potosí 16, de San Luis; y San Juan Bautista 17, de Tabasco. Zalce, Apuntes para la historia, Tomo I, 312-313.
} 
considerarse en la separación de las logias, es cuando supieron de la renuncia del general Díaz a su cargo en la Gran Dieta. Aun cuando Díaz era un dirigente relativamente nominal, a los integrantes de la Dieta les otorgaba seguridad en sus vínculos (organización autorizada) por lo que la renuncia representaba el retiro del reconocimiento. Después de la salida del general Díaz y de varios de sus colaboradores, la Dieta disminuyó su actividad y fue cediendo su autoridad. Al finalizar el siglo, pese a un proyecto que reactivaría la creación de Grandes Logias y su confederalización voluntaria, la Gran Dieta no recuperó su espacio y su poder, como tampoco lo hicieron los masones mexicanos en el siglo $\mathrm{XX}^{18}$.

Reconocido Ermilo G. Cantón, secretario permanente de la Gran Dieta Simbólica, como el principal coordinador, con su muerte, ocurrida en febrero de 1899, se interrumpió el impulso que le proporcionaba a la Dieta. La organización empezó a declinar, a pesar del intento de reactivación de Manuel Leví como una Confederación de Grandes Logias. Con la propuesta de Leví se intentaba conservar la unidad de las Grandes Logias participantes en la Dieta y que aún existían en el país. Al mismo tiempo se alentaba la creación de Grandes Logias en los estados, al proponer tres logias constituyentes y no siete, como en el periodo de Cantón, y se brindaba la opción, si no ocurría tal constitución, de permanecer adscritos a la Gran Logia Valle de México, donde Leví era Gran Venerable Maestro.

Pese a la autonomía que se les otorgaba a los probables participantes, en especial en la administración de los grados masónicos, la propuesta de Leví no tuvo éxito, circunstancia por la cual la Gran Dieta desapareció tranquilamente. Sucedió todo lo contrario con la Gran Logia Valle de México, que continuó ostentándose como la principal obediencia masónica de México $^{19}$. En este tenor, la masonería mexicana enfrentó una serie de dilemas sobre su organización, e incluso sobre su existencia. El primer dilema fue el tipo de estructura que debería tener: Confederación de Grandes Logias o una Gran Logia Nacional -al menos para el REAyA-, luego cuál era la instancia adecuada para reconocer la regularidad y la legitimidad de una Gran Logia. Se agrega a estas cuestiones los nexos que se establecieron con la Revolución mexicana y el régimen que emanó de este movimiento político y armado.

En los primeros años del siglo XX varios masones fomentaron la reinstauración del RNM. Con el fin de legitimarse y alcanzar el reconocimiento del régimen, el restaurado RNM inscribió entre sus integrantes al general Porfirio Díaz y a Francisco de Paula Gochicoa, último Gran Luminar (dirigente) de ese rito. Pese a que estos rechazaron su adhesión, por pertenecer al Supremo Consejo del REAyA, los nacionales continuaron con su labor ${ }^{20}$.

\footnotetext{
18 “Gran Dieta Simbólica de los Estados Unidos Mexicanos” (10 de diciembre de 1899), en CPD-UI.

19 "Gran Dieta Simbólica...", México, diciembre 10 de 1899, en CPD-UI. Procedimientos de la Gran Logia Valle de México, 1903, en Zalce, Apuntes para la historia, Tomo I, 378; Tomo II, 20-21, 368-69. Bianuario de la Muy Respetable Gran Logia Valle de México, 1935 a 1937 (1937): 13. Primer Congreso Masónico Nacional (1926), 28-33.

${ }^{20}$ Entre sus promotores se encontraban Benito Juárez Maza, Juan Sánchez Azcona, Rafael Zubirán Campany, Diódoro Batalla y Jesús Ureta, quienes posteriormente fueron militantes del Partido Democrático, la más seria organización reyista del periodo. Los dirigentes del RNM de 1900-1936 fueron: Benito Juárez Maza, Ignacio
} 
Simultánea a la pretendida reactivación de Manuel Leví, el Supremo Consejo del REAyA, dirigido por el general Jesús Alonso Flores, asumió un rol dirigente a nivel nacional al relacionarse con algunas grandes logias de los estados. Antes de colocarse en el lugar de dirigente, el Supremo Consejo sólo contaba con la adhesión de las Grandes Logias Unida de Veracruz, Cosmos de Chihuahua, Santos Degollado del Distrito Federal e Hidalgo del estado de México. La labor proselitista del Supremo Consejo se extendió hacia organizaciones masónicas del extranjero, principalmente de los Estados Unidos. Otra acción que impulsó el general Flores fue la unificación de las logias de la Ciudad de México, la Valle de México, heredera de la Gran Dieta, y la Santos Degollado. Sin conseguirlo en los primeros intentos, pese a la firma de un protocolo que establecía una nueva Gran Logia, la unificación se efectúo en 1906, cuando ambas logias eligieron como gran maestro a Alberto Pro. ${ }^{21}$.

Sin conciliación masónica absoluta después de la desaparición de la Gran Dieta Simbólica, el Supremo Consejo controló algunas manifestaciones políticas de asociaciones masónicas y mantuvo al general Díaz como su integrante ad-vitam, al lado de otros viejos masones y colaboradores del militar. Estas presencias permiten suponer que una de las causas por las que no fue necesaria la continuidad del esquema de control y de subordinación que inauguró la Gran Dieta en la masonería en México, es que ya había proporcionado el ascenso ritual para algunos políticos, como Bernardo Reyes, Francisco Arce, José Castellot y Jesús Aréchiga, gobernadores de Nuevo León, Guerrero, Campeche y Zacatecas, respectivamente. Gracias a sus ascensos y a sus posiciones políticas, participaron en los distintos órdenes de cuerpos del REAyA e influyeron en la dinámica de las logias que les eran leales en sus estados $^{22}$.

Otro fenómeno que se presentó en el periodo es la aparición de logias que no estaban adscritas a una Gran Logia, ni a algún rito masón en específico, pero sí estaban vinculadas a sociedades religiosas protestantes. Estas relaciones eran frecuentes en las asociaciones que tenían por modelo a los clubes franceses de 1789, debido a su espíritu liberal. Algunos de los partícipes de esos clubes transitaron de la disidencia a la oposición política, al vincularse al Partido Liberal de San Luis Potosí y al antireeleccionismo, acciones políticas que situamos como precedentes de la Revolución mexicana. Un ejemplo es la asociación impulsada por el minero Eulalio Gutiérrez (presidente de la República emanado de la Convención de Aguascalientes) en Concepción del Oro, Zacatecas, pues su presunta logia devino en club político cuasi masón disidente del régimen porfirista. Otro caso es el de las disidencias masónicas arraigadas en las logias de provincia y en los clubes políticos. Como oposicionista,

de la Peña, Manuel Esteban Ramírez, Manuel E. Guzmán. "Porfirio Díaz a José de la Paz Álvarez", Cd. de México (15 noviembre de 1902); "Francisco de P. Gochicoa a José de la Paz Alvarez", Cd. de México (20 de noviembre de 1902), ambas citadas por Zalce, Apuntes para la historia, Tomo II, 4-5.

${ }^{21}$ Zalce, Apuntes para la historia, Tomo II), Bianuario (1937): 13-14.

22 "Bernardo Reyes a José María Mier" (4 de noviembre de 1904), Monterrey, NL, en Condumex. 
Luis J. Zalce describe que el club antireeleccionista de Pachuca, Hidalgo, se integró con masones de distintos ritos, quienes coincidían en las ideas y aspiraciones políticas ${ }^{23}$.

Con frecuencia, las divisiones comenzaron como reacción a la llamada política de conciliación, la que implicaba mantener el programa del liberalismo aunque no se diera su aplicación. Se une la poca respuesta a las aspiraciones políticas de los masones, quienes al no encontrar respuesta satisfactoria concurrieron, sin abandonar su status de masón, a la oposición manifiesta: la moderada del reyismo o la activa del magonismo y el antireeleccionismo. Como resultado, se obtuvo una alta reacción opositora al régimen porfirista. Por ejemplo: al triunfo revolucionario de 1911, las grandes logias de México y de Puebla, y algunos masones de logias del interior del país, reconocieron inmediatamente a Francisco I. Madero como uno de los suyos ${ }^{24}$.

La actitud de algunas logias y órdenes de cuerpos de la Ciudad de México se diferenció de la actitud de tierra adentro, las primeras permanecieron leales al régimen porfirista, aun después de la salida del general Díaz; tal es el caso del Gran Campamento Templario de México y del Consejo Kadosh Porfirio Díaz, al que pertenecieron varios masones que conspiraron contra Madero en $1912^{25}$. Incluso, el Supremo Consejo del REAyA, con José Castellot como Gran Comendador, recomendó prudencia a los clubes dirigidos por masones en relación a los movimientos armados de 1910. Estos datos permiten señalar que las diferentes actuaciones políticas externas implican la redacción de diversas historias de la masonería: de su pluralidad -los ritos-, de sus valores fundadores -comprensión, difusión- y sus alcances geográficos. Se nota que no es la misma historia de la masonería de la Ciudad de México y la trayectoria propiamente de la Gran Logia del Valle de México, que las historias de la asociación en las ciudades del interior del país.

\footnotetext{
${ }^{23}$ Zalce, Apuntes para la historia, Tomo II, 3, 30-32.

${ }^{24}$ Francisco I. Madero (1873-1913) dirigió un movimiento armado en contra del régimen porfirista. Luego del triunfo de la Revolución (1910) y tras unas elecciones, ocupó la presidencia de la República (1911-1913). No concluyó su mandato presidencial, merced a un golpe de Estado. Madero, igual que Díaz, fue masón. El inicio masónico de Madero se suele ubicar en 1890, en la logia Benito Juárez de Coahuila, cuando ésta era parte de la Gran Dieta Masónica. En 1909, Madero intervino en la logia Lealtad de la Ciudad de México, dirigida por Alberto Pro, y luego pasó a la logia Mariano Escobedo de Coahuila. "Francisco I. Madero a Alberto Pro", San Pedro, Coah. (30 de julio de 1909); "Francisco I. Madero a La Resp. Log. Lealtad”, San Pedro, Coah. (30 de julio de 1909), en Madero, 1985. "Gran Logia de Libres y Aceptados Masones de Puebla a Francisco I. Madero" Puebla, Pue. (5 de septiembre de 1912), en Archivo General de la Nación-Fondo Francisco I. Madero. "Comunicación de la Gran Logia de Antiguos, Libres y Aceptados masones 'Valle de México' al maestro masón Porfirio Díaz", Cd. de México (4 de mayo de 1911); "Francisco I. Madero a Gran Logia Valle de México", Cd. Juárez, Chih. (16 de mayo de 1911); "Adolfo M. Isasi a Francisco I. Madero", Cd. de México (11 de mayo de 1911); “Tomás Lorck a Francisco I. Madero”, Zacatecas, Zac. (20 de mayo de 1911), en Fondo Francisco I. Madero-Biblioteca Nacional, Universidad Nacional Autónoma de México.

25 "Tenida blanca del Gran Campamento Templario en homenaje al general Bernardo Reyes", cd. de México, abril 18 de 1913, en Condumex. Zalce, Apuntes para la historia, Tomo II, 30, 44-45.
} 


\section{La masonería del Porfiriato como tema historiográfico}

Al iniciar el texto señalamos que la masonería ha sido analizada como un tópico presente en los tránsitos políticos e ideológicos en México; por sus vínculos con los liberalismos; el ascenso y movilidad de los individuos que utilizaron las redes sociales provenientes de las logias. François-Xavier Guerra y Jean-Pierre Bastian han estudiado la masonería activa en el Porfiriato. El primero estudió las logias, la elite política mexicana en el siglo XIX y cultura política ${ }^{26}$; Bastian examinó las comunidades religiosas protestantes y la masonería durante la república restaurada y el Porfiriato ${ }^{27}$. Los dos usan la misma bibliografía metodológica (Dumont, Agulhon, Habermas, Cochin, Furet y Ferrer Benimeli $^{28}$. Va un panorama de esos estudios.

François-Xavier Guerra sitúa, por primera vez, a la masonería como una sociabilidad moderna en México: del Antiguo Régimen a la Revolución. Luego lo hizo en Modernidad e independencias. Ensayos sobre las revoluciones hispánicas, aquí amplió la definición a otras sociabilidades -las tertulias, las sociedades de amigos y literarias y las academias, enclavadas en las elites del área hispánica-, y contempló la existencia de las prácticas modernas en el resto del subcontinente americano. Es en el ensayo "Lugares, formas y ritmos de la política moderna" donde aborda como tema principal a las logias ${ }^{29}$. Ese texto lo publicó intermedio entre los libros citados. En el artículo define a las logias como una "sociabilidad de tipo nuevo en que se mezclan la igualdad, la filantropía y la ayuda mutua" ${ }^{\prime 0}$. Igualmente las enmarca en la irrupción de las sociabilidades que aparecieron en el siglo XVIII y se desarrollaron en la siguiente centuria en América Latina. En tal perspectiva, considera que la cultura política moderna se originó en la Ilustración y fue puesta en práctica en la Revolución francesa, para luego pasar a la España liberal y al

\footnotetext{
${ }^{26}$ François-Xavier Guerra, "Lugares, formas y ritmos de la política moderna", Boletín de la Academia Nacional de Historia 285 (enero-marzo, 1989): 7-23. Guerra, México: del Antiguo Régimen a la Revolución (México D. F.: FCE, 1992), Tomo I, 165-169. Guerra, Modernidad e independencias. Ensayos sobre las revoluciones hispánicas (México D. F.: FCE, Mapfre, 1993).

${ }^{27}$ Bastian, "El paradigma de 1789. Sociedades de ideas y Revolución Mexicana", Historia Mexicana 1, no. XXXVIII (1988): 79-109. Bastian, Los disidentes, sociedades protestantes y Revolución en México.

${ }^{28}$ Agustín Cochin, Les sociétés de pensée et la démocratie moderne. François Furet, Pensar la Revolución francesa. Maurice Agulhon, su estudio sobre las sociabilidades francesas. Jürgen Habermas, L'espace public. Archélogie de la publicité comme dimension constitutive de la société bougeoise. Louis Dumont, Homo aequalis. José Antonio Ferrer Benimeli, Masonería e inquisición en Latinoamérica durante el siglo XVIII y La masonería española en el siglo XVIII.

${ }^{29}$ Guerra, "Lugares, formas y ritmos de la política moderna". Guerra, México: del Antiguo Régimen, 157-181. Guerra, Modernidad e independencias, 85-113. Guerra y Annick Lempérière coords., Los espacios públicos en Iberoamérica. Ambigüedades y problemas. Siglos XVIII-XIX (México D.F.: FCE, CFEMC, 1998). Alfredo Ávila, "De las independencias a la modernidad. Notas sobre un cambio historiográfico", 76-112, y Elisa Cárdenas Ayala, "Las páginas mexicanas de François-Xavier Guerra: 18 años", 42-75, ambos en Conceptualizar lo que se ve: François-Xavier Guerra. Historiador: homenaje, Erika Pani y Alicia Salmerón coords. (México D.F.: Instituto Mora, 2004).

${ }^{30}$ Guerra, "Lugares, formas y ritmos de la política moderna", 13.
} 
México de entonces. En esta ruta, asevera que el liberalismo mexicano tomó el basamento teórico y lo resumió en la Constitución de 1857.

Para continuar con la descripción del modelo explicativo propuesto por Guerra ubico tal modelo en el conjunto de las publicaciones citadas- es indispensable advertir que el periodo que contempla va de la crisis en el imperio español a la formación y consolidación de las naciones latinoamericanas. Aunque al inicio examinó el caso de México, paulatinamente extendió su auscultación al espacio americano de la corona hispánica. Otra cuestión básica son las unidades de análisis que propuso considerar, para comprender el advenimiento de la modernidad en las sociedades que estudiaba. Lo que propone analizar son "los lugares y las formas en que se efectúa la socialización de los hombres", así como "las nuevas formas de socialización y la construcción y difusión de la modernidad" 31 . Es importante destacar que junto a estas unidades de análisis, no ignora la posibilidad de la convivencia y la sustitución de las prácticas tradicionales ${ }^{32}$ en los actores que protagonizaron el avance de la modernidad. Por ésta postula la invención del individuociudadano, como el actor eje de la sociedad. Acerca del individuo moderno, entre otras expresiones anotó:

Ese hombre nuevo es un hombre individual, desgajado de los vínculos de la antigua sociedad estamental y corporativa; la nueva sociedad, una sociedad contractual, surgida de un nuevo pacto social; la nueva política, la expresión de un nuevo soberano, el pueblo, a través de la competición de los que buscan encarnarlo o representarlo ${ }^{33}$.

En la exposición sobre las sociabilidades modernas, proyecta como "el modelo más acabado" a la logia masónica, junto con el club revolucionario -que son las contrapartes francesas de las sociétés de pensée que estudiaron en su momento Cochin y Furet, en sus respectivas investigaciones sobre la Revolución francesa-. Guerra propone a la logia como el modelo moderno, lo es por la adhesión libre de sus integrantes y por la finalidad de las mismas, que es "pensar [y], elaborar la opinión".

Guerra explica que la novedad, frente al orden del antiguo régimen, es el reclutamiento para las reuniones sociales. La integración no atiende primordialmente la condición estamental de cada individuo, pues estriba en la libertad en ejercer para integrarse en reuniones interestamentales o interclase. Las posibilidades de los individuos la otorga la "igualdad abstracta" que poseen, al intervenir como sujetos pensantes. Expone que esas prácticas las ejercieron primero las elites culturales; luego se extendió al resto de

\footnotetext{
${ }^{31}$ Guerra, Modernidad e independencias, 87.

${ }^{32}$ Expresa que las prácticas tradicionales son las que se basan en los lazos concretos personales y familiares, en jerarquías aceptadas en la comunidad y el grupo al que se pertenece. Guerra, México: del Antiguo Régimen, Tomo I, 127-145.

${ }^{33}$ Guerra, Modernidad e independencias, 13.
} 
los individuos, conforme se avanzó en la instauración del liberalismo y fue asunto común las prácticas políticas modernas. El cumplimiento de la finalidad, en la perspectiva de Guerra, contribuyó para que la política tuviera un ámbito autónomo. En oposición al antiguo régimen, donde

La sociedad no se modifica para convertirse en un cuerpo político, y no hay personal político especializado, pues la política sólo es una extensión del poder social de los actores colectivos [...] en el mundo político moderno, la política tiene sus propios especialistas, los políticos, encargados de preparar y luego recoger esta voluntad del individuo en tanto homo politicus, el ciudadano ${ }^{34}$.

Guerra expresa que las logias son un producto de la modernidad "no sólo [por ser] el lugar en donde se elabora la opinión pública y en el que se enfrentan hombres en busca del poder público; sino también, y quizá sobre todo, por ser lugares de aprendizaje y de transmisión de la ideología moderna", misma que contribuirá, seguimos su argumentación: "a la invención y arraigo del individuo". Aunque Guerra también aclara, la paradoja de un sistema que querría hacer coincidir el poder con el pueblo, el sistema engendra elites políticas, con una base de poder que es el conocimiento de los mecanismos, de una imagen de lo social y de un lenguaje profundamente extraño a los de una sociedad -que continúa con un arraigado predominio holista- ${ }^{35}$.

Destaquemos: Guerra sitúa a las logias como centro de instrucción política y cultural; hace notar la intervención de las logias como actores sociales en el espacio público político; y, la participación en el proceso de secularización de la sociedad, entre otros temas. En el caso de las obras de François-Xavier Guerra, nos interesa mencionar la ubicación de la logia masónica como el lugar donde se proyectó la nueva sociabilidad, allí la igualdad abstracta del individuo está acompañada de la voluntad para optar por la adhesión o el rechazo a la reunión en la logia. Esta mirada es la que contrasta con las logias definidas como facciones políticas (Garner y Tello Díaz), pues allí el individuo, si es que es tal, pertenece más a la clientela dirigida por un caudillo político o militar. En el faccionalismo no existe el sujeto normativo y las logias son instancias mediadoras "para satisfacer ambiciones" -traslado las palabras de Michael P. Costeloe-, y no se considera la voluntad individual de los congregados, sino sólo de quien los dirige.

Un segundo elemento es la aprehensión de las logias en el largo trazo de la modernidad. En el análisis de la permanencia y la difusión de las sociabilidades modernas, las sostiene como el modelo "acabado" -retomo la expresión de Guerra-. Así se puede observar implícitamente en Los espacios públicos en Iberoamérica, donde son analizadas diversas formas de sociabilidad que participaron en la construcción del espacio público

\footnotetext{
${ }^{34}$ Guerra, México: del Antiguo Régimen, Tomo I, 165.

${ }^{35}$ Guerra, México: del Antiguo Régimen, Tomo I, 165.
} 
político. En esa obra colectiva se pone atención a las permanencias, las resistencias y las adaptaciones, así como las novedades y las rupturas en las mutaciones culturales que ocurrieron a fines del siglo XVIII y la primera mitad del XIX.

La idealización de las logias proviene del modelo de las sociedades de pensamiento. Guerra escribió:

La elaboración constante de la opinión, del consenso de la sociedad -la del grupo político-, demanda en efecto un esfuerzo considerable de los asociados: reuniones que convocar, mociones que preparar y que votar, mensajes que enviar a sociedades hermanas o filiales ${ }^{36}$.

La idealización contribuye a desdibujar la masonería y privilegiar a las logias. Es tanto como ubicar perfectamente un árbol, definir su trayectoria en el hábitat, pero es despreciado el bosque al que pertenece, es decir: ignora la organización masónica y la lógica de su funcionamiento. A lo sumo, a ésta la alude como "redes de logias" que tienen un programa político común. Consideramos cerrada la definición de la masonería, tanto que proporciona un retorno a la bibliografía de las facciones. Ocurre al no tratar a las logias como parte de la masonería, pues no discurre por su estructura, ni en sus rasgos culturales convergentes y divergentes con la modernidad, ni tampoco en las cargas culturales y políticas que llevan consigo los masones al ingresar o, incluso, rechazar su adhesión a la masonería. Esta observación, por cierto, coincide con la crítica que le hace José Antonio Aguilar Rivera a la propuesta del "sistema moderno de poder" de Guerra, pues éste privilegia a las sociabilidades y no advierte "la importancia de la dimensión institucional [el modelo liberal-constitucional] del proceso político moderno"37.

En el caso de Jean-Pierre Bastian, él analizó a la masonería mexicana. Lo hizo con relación al surgimiento de las sociedades de protestantes religiosos mexicanos, en la segunda mitad del siglo $\mathrm{XIX}^{38}$. El examen de esas asociaciones -a las que designa con el término explicativo de "sociedades de ideas", traslada el de sociétés de pensée de Agustín Cochin- le ayudan para establecer una genealogía de las etapas de la modernidad en México, así como para tipificar las rupturas y las mutaciones culturales que provinieron de

\footnotetext{
${ }^{36}$ Guerra, México: del Antiguo Régimen, Tomo I, 165.

37 José Antonio Aguilar Rivera, En pos de la quimera. Reflexiones sobre el experimento constitucional atlántico (México D. F.: FCE, CIDE, 2000), 29.

38 Bastian, Los disidentes, sociedades protestantes y Revolución en México. Posteriormente efectúo investigaciones acerca de la relación entre el protestantismo religioso y la masonería en España y Cuba, donde sigue las líneas planteadas en su trabajo doctoral para examinar los lazos que se tejieron entre ambas congregaciones y la intervención de éstas en "la lucha por la modernidad laica en búsqueda de un orden democrático y secularizado que pasó por la confrontación con el catolicismo imperante desde la segunda mitad del siglo XIX", Bastian, "Los dirigentes protestantes españoles y su vínculo masónico, 1868-1939: hacia la elaboración de un corpus", en La masonería en Madrid y en España del siglo XVIII al XXI, Ferrer Benimeli coord. (Zaragoza: Gobierno de Aragón, 2004), Tomo II, 1051.
} 
las capas sociales subordinadas del interior del país. Las rupturas le permiten mostrar un rostro de la oposición sociopolítica y cultural que enfrentó a las elites autodenominadas como liberales. Otra cuestión de resaltar es el uso de dos perspectivas que también están en el modelo explicativo de la modernidad: el paradigma de la secularización y la comparación entre las amplias áreas de Hispanoamérica y de la Europa latina ${ }^{39}$.

Con base en el modelo explicativo de la modernidad, Bastian plantea que los nexos entre la masonería y las sociedades protestantes religiosas están inscritos en el amplio contexto de interrelaciones de los individuos que, además de participar en ambas sociabilidades, pueden estar igualmente inmersos en otras sociedades de ideas anticlericales y anticonservadoras. El examen de ambas asociaciones, le permite considerar que son los contramodelos de las sociedades tradicionales y corporativizadas, pues sirvieron como laboratorios de las minorías políticamente activas para elaborar alternativas sociales y políticas que desembocarían en las reformas liberales decimonónicas en Latinoamérica. Bastian insiste, como Guerra lo hizo en su momento, con las sociabilidades culturales de los albores del siglo XIX: las sociedades de ideas, al ser portadoras de la modernidad, propusieron y configuraron nuevas formas de organización de lo social, centradas en el individuo como actor político y social, y no sobre los antiguos cuerpos.

Bastian asevera, retomando a François Furet, que las asociaciones masónicas son novedosas porque se constituyen con integrantes despojados de toda particularidad concreta y de su real existencia social; y, se caracterizan más por el hecho "de que cada uno de sus miembros tiene solamente una relación con las ideas, con los fines". Anticipando con ello el funcionamiento de la democracia, por la igualdad abstracta de los individuos, además estos se educaban en la práctica política moderna, en cuanto ejercían su soberanía como parte del pueblo de los electores ${ }^{40}$.

Respecto a las etapas de la modernidad, advierte que se deben atender tres cuestiones: lo primero es que a largo plazo hay varios momentos y que sus ritmos no son similares. La segunda es la atención a la localización de las asociaciones, pues éstas ayudan a fijar la geografía de las mutaciones políticas. En la tercera considera a las sociedades de ideas, en su conjunto (además de la masonería y el protestantismo, están el espiritismo, las mutualistas y las redes de clubes políticos de liberales radicales), fueron "redes prepolíticas portadoras de la modernidad en contra de la sociedad profunda, corporativa", por lo que no

\footnotetext{
${ }^{39}$ Bastian, "Introducción", en Protestantes, liberales y francmasones. Sociedades de ideas y modernidad en América Latina, siglo XIX, Bastian coord. (México D. F.: FCE, 1993), 7-14. Bastian, Protestantismos y modernidad latinoamericana. Historia de unas minorías religiosas activas en América Latina (México D. F.: FCE, 1994). Bastian, La mutación religiosa de América Latina. Para una sociología del cambio social en la modernidad periférica (México D. F.: FCE, 1997). Bastian, "Introducción", en La modernidad religiosa: Europa latina y América Latina en perspectiva comparada, Bastian coord. (México D.F.: FCE, 2004).

40 "Introducción", en La modernidad religiosa, 8.
} 
puede sólo clasificarlas como frentes anticatólicos y antagónicos a las fuerzas políticas conservadoras ${ }^{41}$.

Bastian sitúa dos momentos decimonónicos: el del primer liberalismo latinoamericano. Éste tiene como marco de referencia a las primeras constituciones de los nacientes Estado-nación, donde si bien la exclusividad de la religión católica en los estados fijó a las logias como portadoras de un liberalismo moderado que "buscó desesperadamente conciliar catolicismo y modernidad, en un intento por reformar desde arriba una sociedad cuyas reformas fueron frenadas por el propio peso corporativo". Tal liberalismo hizo frente a la romanización del catolicismo latinoamericano y a las resistencias de la sociedad tradicional. La reacción de las minorías liberales fue una paulatina radicalización anticatólica y anticlerical en la segunda mitad del siglo XIX.

El segundo momento es el de la delimitación del espacio público liberal. Éste corresponde al lapso de conquista del poder y cuando se implantaron los principios liberales a través de nuevas constituciones y leyes. Esto, admite, que si bien fue de peso precario, abrió el paso para la difusión de nuevas asociaciones modernas, las que ampliaron el frente liberal conformado casi exclusivamente por las logias. Pero advierte, la multiplicación de las sociedades de ideas son indicios de la lucha interna en el seno del liberalismo. Referente entonces al enfrentamiento entre los liberales enquistados en el poder (proclives a la conciliación con la Iglesia católica), además de agrupados en la Gran Dieta Simbólica, están los liberales radicales que no tenían entre sus prioridades el desarrollo económico, sino la educación para los sectores sociales no beneficiados por "el orden y el progreso", estaban integrados en las logias de provincia y en obediencias disidentes a la Gran Dieta Simbólica.

En la obra de Bastian se nota la revisión de textos producidos por masones -revistas y periódicos- y libros, donde se reporta la actividad de estos sujetos. En los documentos exploró la afiliación de los individuos, el nivel de participación en las labores masónicas y el tipo de interrelación que estableció cada individuo entre la masonería y el protestantismo religioso. Con la información obtenida presentó la trayectoria de las sociedades de ideas y las diferencias de organización y funcionamiento. En la masonería da cuenta de las tensiones y diferencias entre los masones, las logias, las obediencias escocés y nacional, así como los proyectos políticos presentes en estos actores, quienes estaban inmersos en el espectro del liberalismo, aunque no estaban todos comprometidos o adheridos al gobierno porfirista. Muestra en el interior de la república, a esas sociedades como núcleos sociopolíticos donde se gestó la ruptura con el régimen, argumentando la desviación del liberalismo.

\footnotetext{
${ }^{41}$ Bastian, "Ritmos de secularización y modernidad religiosa en México, siglo XIX", en Proyectos políticos, revueltas populares y represión oficial en México, 1821-1965, Jane-Dale Lloyd y Laura Pérez Rosales coords. (México D.F.: Universidad Iberoamericana, 2010), 67-88.
} 


\section{La historiografía masónica mexicana}

Aquí revisamos las obras de José María Mateos, Historia de la masonería en México; de Richard Chism, Una contribución a la historia masónica de México; y, de Luis J. Zalce, Apuntes para la historia de la masonería en México. Ellos plantearon, en sus respectivos textos, narrar la trayectoria de la masonería en México. Por sus años de vida pública y masónica atendieron primordialmente el siglo XIX y tuvieron como un masón destacado al general Porfirio Díaz. Destaquemos de estos individuos su admisión explícita de ser masones y el interés de que los textos fueran leídos principalmente por las comunidades masónicas del país ${ }^{42}$. Esta situación les consiente ser citados como las referencias básicas en las investigaciones y ensayos que abordan a la asociación.

Las obras de los masones Mateos, Chism y Zalce comprenden desde sus orígenes hasta los días próximos a los autores. Los autores escriben como lectores, actores y testigos de la actividad masónica en México, y no como historiadores. Otros que sí son clasificados como historiadores son la generación de masones que redactaron sus reflexiones acerca de la intervención de la francmasonería en los primeros años del estado independiente (Servando Teresa de Mier, Lorenzo de Zavala, José María Luis Mora, José María Bocanegra, José María Tornel. Los antimasones son Carlos de Bustamante y Lucas Alamán).

Las obras de Mateos, Chism y Zalce son textos testimoniales. Fueron redactadas con base en la información oral reunida por los autores. Chism cita entrevistas con los masones Porfirio Díaz y Alfredo Chavero. También dan cuenta de documentos consultados en archivos privados y acervos masónicos, y la escasa bibliografía existente en los días de redacción. Así lo muestran Zalce y Chism, ellos asientan las resoluciones publicadas en los órganos de información de las logias. Además presentan los datos elaborados en el transcurso de su vida en las logias y en el espacio público.

Chism considera a Mateos como el decano de la masonería mexicana, aserto que admite Zalce. Este hecho no puede considerarse como una anécdota más, o remitirse a las notas de referencia, pues tal aceptación colocó a Mateos como la autoridad informativa masónica más importante en el México decimonónico; luego, Zalce lo será para la primera mitad del siglo $\mathrm{XX}^{43}$.

\footnotetext{
${ }^{42}$ Salvo Chism, quien provenía de las logias estadounidenses, Mateos y Zalce ostentaron los máximos grados masónicos y ocuparon las direcciones nacionales de sus respectivos ritos masónicos. Para seguir su trayectoria también véase: Manuel Esteban Ramírez, Apuntes sintéticos sobre la masonería en México durante los años de 1806 a 1921 por el Gran Luminar, gran maestro de orden del Rito Nacional Mexicano (México D.F.: Imprenta Taller linotipografía Soria, 1921).

${ }^{43}$ Ramírez, Apuntes sintéticos sobre la masonería. Luis J. Zalce "Informe del muy respetable gran maestro Luis J. Zalce", 290-303, en Primer Congreso Masónico Nacional (México D.F.: Ed. Secretaría del Congreso, 1925). Ramón Martínez Zaldúa, La masonería en México (México D.F.: Publicaciones Claridad, s. f.). Julián Gascón Mercado, Los primeros masones y la formación del Supremo Consejo de México, (Prol. Agustín
} 
Siendo narraciones lineales, en el transcurso del relato los autores se detienen en algunos episodios de la trayectoria de la masonería mexicana. Lo hacen para citar los nombres y los argumentos que se esgrimieron para justificar las fracturas y las alianzas que ocurrieron en la organización de las asociaciones masónicas existentes en el país. Reseñan los reclamos por una mayor participación en los órganos de dirección -aumento de grado masónico, autonomía de las logias con respecto a las Grandes Logias, la inclusión de masones en las logias de grados masónicos superiores-. Luego, ante la ausencia de negociación, relatan cómo surgieron disidencias que debilitaban la dirección masónica o la emergencia de fracturas que generaron la aparición de nuevas organizaciones masónicas. En cambio, fueron equilibristas para hacer notar la interacción entre lo interior y "el exterior" de la asociación. Presentan una masonería protagonista en la vida política del país.

La atención a ciertos actos es donde situamos el objetivo principal de las obras de Mateos, Chism y Zalce. Fue para disentir con un órgano de dirección masónica y para defender a su respectiva asociación; el acto era para proclamar la legitimidad de su organización (los autores le llaman principio de regularidad ${ }^{44}$ ). En el caso de José María Mateos, publicó su libro entre 1879 y 1884 . El texto apareció en el periódico masónico La Tolerancia, órgano del Rito Nacional Mexicano (en adelante RNM). Si bien su objetivo general era presentar la historia de la masonería en México y la fundación del RNM, el interés implícito es defender a este Rito de las descalificaciones de legitimidad masónica y reconocimiento que le infringieron varios directores del Rito Escocés Antiguo y Aceptado (en adelante REAyA), quienes pretendían el control de la actividad masónica en México. Mateos anotó en el prólogo de su texto:

Si se estudia este Rito [el Nacional] en su origen, en sus principios masónicos y políticos, en fin, en todos sentidos y bajo el punto de vista de la necesidad que lo hizo nacer, y lo mantiene hasta hoy, libre e independiente en la República mexicana, no se hallarán en él esos motivos de irregularidades que sólo existen en la imaginación de aquellos que por mucho tiempo han vivido como hijos espurios [refiere al Supremo Consejo del REAyA], y que legitimados después por no dar más escándalo a la sociedad, muy pronto han olvidado su modo de ser anterior ${ }^{45}$.

\footnotetext{
Arriaga Rivera, México D.F.: spi, 1987, $2^{a}$ edición). J. Jesús Vázquez Leos, Liberalismo y masonería en San Luis (San Luis Potosí: spi. 1996). Alejandro Reyes Bravo, Cronología masónica (México D.F.: Ed. autor, 2000). Octavio Casa Madrid Mata, Los origenes de la masonería en México (México D.F.: Academia de historia de la masonería, 2003).

${ }^{44}$ El principio de regularidad (se dice "logia regular") refiere que una Gran Logia debe ser legalmente establecida por otra Gran Logia reconocida por tres o más logias regularmente constituidas. Manuel Rodríguez Castillejos, La regularidad en México, y un análisis gráfico de la genealogía mexicana (México D.F.: spi, 2006).

${ }^{45}$ Mateos, Historia de la masonería, 2.
} 
El masón estadounidense Richard Chism publicó Una contribución a la historia masónica de México en 1899. El texto apareció originalmente en el periódico masónico The American Tyler (Michigan, EUA). En México, el libro fue impreso en el departamento de minería, de la Secretaría de Fomento. Su circulación concurrió en el marco del conflicto entre la Gran Dieta Masónica de México y el Supremo Consejo. Estas organizaciones disputaban la dirección masónica del REAyA en México, a finales del siglo XIX. El objetivo de Chism era refutar las declaraciones estadounidenses que negaban autoridad al Supremo Consejo, por considerar que era un cuerpo ilegal por su origen y procedimiento. En cambio, los estadounidenses otorgaban reconocimiento a la Dieta Masónica. Más todavía, expresaban que en México no existió actividad masónica regular antes de la formación del primer Supremo Consejo mexicano, en la década de 1860. Lo enunciaron para deslegitimar la autoridad del máximo cuerpo masónico.

Luis J. Zalce y Rodríguez publicó Apuntes para la historia de la masonería en México, en 1950. El interés explícito para circular su obra, era relatar:

Las actividades de [sus] antecesores, [que] inspirados en el concepto que de las prácticas y enseñanzas masónicas se formaron en etapas diversas bajo la influencia del medio social en que vivieron, medio cambiante por las persecuciones de que llegaron a ser objeto, o por la influencia de la política, o por la evolución natural en las sociedades humanas ${ }^{46}$.

Zalce narra la trayectoria de una dispersa masonería decimonónica -en especial la del RNM- a la formación de las grandes logias estatales. Él se oponía a la centralización que se pretendió ejercer a fines del siglo XIX con la Gran Dieta. Zalce fue proclive al establecimiento de grandes logias regionales o estatales y a la confederalización de la actividad masónica en México ${ }^{47}$.

Un contra relato de los textos de Mateos, Chism y Zalce, son los libros De Cabarrús a Carranza; la legislación anticatólica en Méjico y La masonería en la historia y las leyes de Méjico ${ }^{48}$, ambos de Jesús García Gutiérrez. Los firmó con el seudónimo de Félix Navarrete $^{49}$. El autor considera el anticlericalismo de las constituciones de 1857 y 1917

\footnotetext{
${ }^{46}$ Zalce, Apuntes para la historia, Tomo I, VIII.

${ }^{47}$ Zalce, "Informe del muy..." y Zalce, Apuntes para la historia.

${ }^{48}$ Félix Navarrete (Jesús García Gutiérrez), La masonería en la historia y en las leyes de Méjico (México D.F.: Ed. Jus, 1957). Félix Navarrete (Jesús García Gutiérrez), De Cabarrús a Carranza. La legislación anticatólica en Méjico (México D.F.: Ed. Jus, 1957). Jaime Del Arenal Fenochio, "La otra historia: la historiografía conservadora", en Tendencias y corrientes de la historiografia mexicana del siglo XIX, Conrado Hernández coord. (Zamora: El Colegio de Michoacán, 2003), 63-90. Nora Pérez Rayón, "El anticlericalismo en la historia de México, una visión clerical. La acción anticatólica en México de Jesús García Gutiérrez, Pbro. E historiador, 1939”, en Horizontes y códigos culturales de la historiografia, Saúl Jerónimo, Danna Levin y Columba González, coords. (México D.F.: Universidad Autónoma Metropolitana - Iztapalapa, 2008), 161-204.

49 Jesús García Gutiérrez / Félix Navarrete (Huixquilucan, Estado de México, 1875 - Ciudad de México, 1958): Sacerdote e historiador atento a la Iglesia novohispana y los conflictos entre ésta y el Estado mexicano.
} 
como el resultado de la intervención directa de la francmasonería mexicana para "esclavizar a la Iglesia católica". En la introducción de La masonería... asentó:

La mano que ha ido forjando, a través del tiempo y de los gobiernos, esas cadenas y las ha unido en los puntos en que aparecen rotas, esa mano es la masonería. Por eso estudio en este libro lo que es, en realidad, la masonería, no lo que dicen para despistar; dónde nació, sus actividades en España, la madre patria de donde nos venía lo bueno y lo malo; su influencia en la historia y en las leyes de Méjico y, para completar la obra y los términos en que la han condenado los pontífices romanos, a partir de Clemente XII (p. 7).

El libro La masonería... está integrado con cuatro partes y un apéndice. En la primera refiere los orígenes históricos de la masonería y su simbolismo. La segunda trata la presencia de la asociación en varias secuencias de la historia política de México. Es la sección más amplia del volumen. La tercera parte aborda la legislación que se presume como obra de los masones y su ideología. Este tema lo trata con detenimiento en De Cabarrús a Carranza; la legislación anticatólica en Méjico. La cuarta parte atiende las condenas pontificias a la masonería y otras sociedades secretas. El apéndice contiene una lista de los "gobernantes de Méjico masones comprobados"50.

Para redactar La masonería... Navarrete, al tenor de "asentar lo dicho en documentos bien comprobados, excluyendo por completo el 'se dice"”, consultó un conjunto de libros, folletos y periódicos, casi todos elaborados por masones y escritores poco comprometidos con el "clericalismo". Con el anverso de la información, redactó su historia. Pese a la denuncia que hace Navarrete, del afán esclavizador del Estado hacia la Iglesia, no va por la ruta de la tesis de la conspiración coyuntural, sino de un programa permanente de la masonería en contra de la Iglesia. La narración muestra una asociación que intenta desplazar a la Iglesia católica como institución pública, además de que colabora con operación política y aporta un discurso al Estado.

El hilo narrativo no fue el desvelo de los secretos de la sociedad, era denunciar la presunta influencia que tuvo en la historia de México. Citémosle, para dar cuenta de ello:

\footnotetext{
Utilizó el seudónimo de Félix Navarrete en los libros donde exhibió su militancia católica, como Sí hay persecución religiosa en México: ;Aqui están las pruebas! (1935) y en La lucha entre el poder civil y el clero a la luz de la historia: o sea, comentario al estudio histórico y jurídico del señor licenciado don Emilio Portes Gil, procurador general de la República (1935).

50 Aquí cita a Guadalupe Victoria, Vicente Guerrero, Anastasio Bustamante, Manuel Gómez Pedroza, Antonio López de Santa Anna, Valentín Gómez Farías, Nicolás Bravo, Mariano Paredes y Arrillaga, Mariano Arista, Juan B. Ceballos, Manuel María Lombardini, Ignacio Comonfort, Benito Juárez, Juan N. Almonte, Maximiliano I, Porfirio Díaz, Manuel González, Francisco I. Madero, Emilio Portes Gil, Venustiano Carranza, Adolfo de la Huerta, Plutarco Elías Calles, Manuel Ávila Camacho, Lázaro Cárdenas y Miguel Alemán. Navarrete, La masonería, 239-246.
} 
¿Calles era masón? He aquí, a este respecto, dos hechos muy significativos. Por confesión propia, hecha pública por medio de los periódicos, emprendió la tarea de proseguir y completar la obra de la Reforma y de 1917 y no cejó en su tarea, a pesar de los disgustos que debe haberle ocasionado personalmente y de los graves perjuicios que acarreó a la nación y ya queda demostrado que la obra que con tanta tenacidad emprendió y prosiguió, fue obra de la masonería.

El segundo. A raíz de promulgada la ley Calles, en julio de 1926, la Gran Logia del Valle de México acordó concederle una medalla de oro y el Gran Comendador de la dicha Logia, Esteban Ramírez, se la puso en ceremonia pública y solemne. Los periódicos dieron la noticia y algunos publicaron una fotografía del acto de la imposición ${ }^{51}$.

El volumen no tiene un apartado de bibliografía, pero Navarrete cita en el cuerpo del texto a los autores y libros que consultó. Los documentos guía para su relato son Historia de la masonería en México desde 1806 hasta 1884 de José María Mateos y El Vaticano y los masones de Leo Taxil. Para sus días, hizo puntual seguimiento de lo escrito por el expresidente Emilio Portes Gil ${ }^{52}$.

Los textos de los masones Mateos, Chism y Zalce, y el de Navarrete son obras de índole político. Dan cuenta de asociaciones formales con direcciones asignadas y elegidas por formas previamente acordadas; negociaciones y conflictos entre los integrantes de las logias, las grandes logias y las redes de relaciones masónicas; refieren ritos, símbolos, discursos y las formas de dominación.

\section{Epílogo: El masón Porfirio Díaz en la historiografía masónica mexicana}

Para el examen del masón Porfirio Díaz partamos de Mateos, por ser el texto más antiguo. La primera vez que refiere al general Díaz es en el capítulo 19 (de 28 capítulos). Es mencionado como uno de los militares republicanos que colabora con el gobierno de Benito Juárez, durante la Intervención francesa, en 1862 (pág. 165). Como masón es citado en el apartado 20, allí es aludido como uno de los integrantes del Supremo Consejo instalado en la ciudad de Veracruz y como parte de quienes optaron por reunir los superiores órdenes de cuerpo masónico del REAyA existentes en el territorio mexicano, 1868 (págs. 224-232). En el siguiente capítulo, Mateos transcribe un documento de 1870, a través del cual se consulta la posibilidad de reconocimiento del Rito Escocés Antiguo y Reformado y de sus vínculos con el RNM. Llama la atención que los masones firmaron con seudónimo, no así Porfirio Díaz (pág. 270). El capítulo 25 lo destinó para reseñar los

\footnotetext{
${ }_{52}^{51}$ Navarrete, La masonería, 172-173.

52 Para un panorama de la labor masónica de Emilio Portes Gil, "Emilio Portes Gil: actuación de un revolucionario en plena crisis política presidencial" y "Breve bibliografía del Lic. Emilio Portes Gil", Supremo Consejo XVI, no. 93 (marzo-abril 1986): 1-4.
} 
"acontecimientos políticos que han influido notablemente en la masonería de toda la República, principalmente en el RNM y sus consecuencias: año de 1876 a 1879”. Aquí trata la interacción de los masones en relación a la revuelta que encabezó Díaz y la cual le facilitó para arribar a la presidencia de la República (págs. 335-345). La última cita está en la página 365, en ella trae a cuento que el multicitado hermano Porfirio Díaz fue elegido, en ausencia, como Muy Respetable Gran Maestro de la Gran Logia del Distrito Federal, lo vincula a la separación entre el Supremo Consejo (la asociación de los masones con grado 33) y las logias simbólicas asentadas en territorio mexicano.

Destinado el libro del norteamericano Richard Chism a defender la legitimidad del Supremo Consejo establecido en el territorio mexicano (lo hace ante los embates de la masonería estadounidense), Porfirio Díaz es tratado, desde el inicio, como un general masón de grado 33. Chism lo aborda en el contexto del "renacimiento del rito escocés" y la mudanza de los masones nacionales a las logias escocesas (caps. V-VII; págs. 17, 61). A diferencia de Mateos, que trata a Díaz como un masón activo más, el masón norteamericano lo coloca como protagonista y distante de las logias simbólicas, incluso de la Gran Dieta (págs. 61-62, 113, 116-128).

Luis J. Zalce da entrada a Díaz como militar. Lo hace igual que Mateos; pero concede una cortesía: lo cita primero, junto al grupo de hombres armados "ya consagrados definitivamente por la historia (pág. 218)" que eran proclives al presidente Juárez. En páginas posteriores lo refiere como "ilustre hermano" (el tratamiento seguirá en los siguientes capítulos) que pasó del RNM al REAyA, además como integrante Supremo Consejo instalado en Veracruz (Tomo I, pág. 241). En adelante el tratamiento oscilará entre masón con actividad política evidente y presidente de la República.

Cerremos las referencias y señalemos: los libros de Mateos, Chism y Zalce pueden definirse como densos apuntes sobre las formas masónicas que instruyen para formular opiniones: saber leer los signos y los discursos; conocer las ceremonias y los temas de discusión en las tenidas; escribir lo aprendido; e interactuar en las discretas tenidas y en las sociabilidades donde participan como ciudadanos de la República. En el último rubro hay un tópico que interesa en este ensayo y es evidente en los textos multicitados: marcan, que si bien en las logias es donde se adquiere una identidad, los lugares no encierran a sus integrantes; el fin no es la exclusividad, pues son espacios que configuran la intermediación. Colocado el masón como un actor de la dramaturgia masónica, su biografía "profana y masónica" da cuenta que interviene en su localidad y en la amplia red social que ofrece una gran logia regional o nacional y un Estado nacional.

Los tres autores refieren explícitamente a Porfirio Díaz como un masón con grado 33 e integrante permanente del Supremo Consejo. Esta actividad lo coloca en la dirección del REAyA, e incluso del RNM. Chism y Zalce miran como un desacierto la vinculación 
con la Gran Dieta y en tal tenor responsabilizarán a Ermilo G. Cantón como responsable de la citada asociación centralista. En fin, el general Díaz fue un masón no deturpado.

\section{Fuentes}

Archivo General de la Nación-Fondo Francisco I. Madero.

Archivo Condumex (Fundación Carso).

Colección Porfirio Díaz, Universidad Iberoamericana.

Fondo Francisco I. Madero-Biblioteca Nacional, Universidad Nacional Autónoma de México.

\section{Bibliografía}

Bastian, Jean Pierre. "Las sociedades protestantes y la oposición a Porfirio Díaz, 18771911”. En Historia Mexicana XXXVII, no. 3 (1988): 469-512.

Bastian, Jean Pierre. "El paradigma de 1789. Sociedades de ideas y Revolución Mexicana". En Historia Mexicana XXXVIII, no. 1 (1988): 79-109.

Bastian, Jean Pierre. Los disidentes, sociedades protestantes y Revolución en México, 1879_ 1911. México D. F.: FCE, El Colegio de México, 1989.

Bastian, Jean Pierre. "Introducción”. En Protestantes, liberales y francmasones. Sociedades de ideas y modernidad en América Latina, siglo XIX. Coordinado por Jean Pierre Bastian. México D. F.: FCE, CEHILA, 1993.

Bastian, Jean Pierre. "La francmasonería dividida y el poder liberal en México, 18721911”. En Masonería española y América. Coordinado por José Antonio Ferrer Benimeli. Zaragoza: Centro de Estudios Históricos de la Masonería Española, 1993.

Bastian, Jean Pierre. "Las sociedades protestantes y la oposición a Porfirio Díaz en México, 1877-1911”. En Protestantes, liberales y francmasones. Sociedades de ideas y modernidad en América Latina, siglo XIX. Coordinado por Jean Pierre Bastian. México D. F.: FCE, CEHILA, 1993.

Bastian, Jean Pierre. Protestantismos y modernidad latinoamericana. Historia de unas minorías religiosas activas en América Latina. México D. F.: FCE, 1994.

Bastian, Jean Pierre. "La francmasonería en la historiografía mexicanista". En Masonería española entre Europa y América. Coordinado por José Antonio Ferrer Benimeli. Zaragoza: Gobierno de Aragón, 1995.

Bastian, Jean Pierre. "Las logias francmasonas españolas del siglo XX ¿qué tipo de sociabilidad?" En La masonería en la España del siglo XX. Coordinado por José Antonio Ferrer Benimeli. Toledo: Universidad de Castilla-La Mancha, 1996. 
Bastian, Jean Pierre. La mutación religiosa de América Latina. Para una sociología del cambio social en la modernidad periférica. México D. F.: FCE, 1997.

Bastian, Jean Pierre. "Las redes francmasonas y protestantes en el movimiento independentista cubano, 1868-1898”. En La masonería española y la crisis política del 98. Coordinado por José Antonio Ferrer Benimeli. Zaragoza: Centro de Estudios Históricos de la Masonería Española, 1999.

Bastian, Jean Pierre. "Masonería y protestantismo en España: un balance historiográfico". En La masonería española en el 2000. Una revisión histórica. Coordinado por José Antonio Ferrer Benimeli. Zaragoza: Gobierno de Aragón, 2001.

Bastian, Jean Pierre. "Los dirigentes protestantes españoles y su vínculo masónico, 18681939: hacia la elaboración de un corpus". En La masonería en Madrid y en España del siglo XVIII al XXI. Coordinado por José Antonio Ferrer Benimeli. Zaragoza: Gobierno de Aragón, 2004.

Bastian, Jean Pierre. “Introducción”. En La modernidad religiosa: Europa latina y América Latina en perspectiva comparada. Coordinado por Jean Pierre Bastian. México D. F.: FCE, 2004.

Bastian, Jean Pierre. "Ritmos de secularización y modernidad religiosa en México, siglo XIX”. En Proyectos políticos, revueltas populares y represión oficial en México, 1821-1965. Coordinado por Jane-Dale Lloyd y Laura Pérez Rosales. México D. F.: Universidad Iberoamericana, 2010.

Bianuario de la Muy Respetable Gran Logia Valle de México, 1935 a 1937. México D. F., 1938.

Casa Madrid Mata, Octavio. Los orígenes de la masonería en México. México D. F.: Academia de historia de la masonería, 2003.

Chism, Richard P. Una contribución a la historia masónica de México. México D. F.: Imprenta del Minero, 1899.

Del Arenal Fenochio, Jaime. "La otra historia: la historiografía conservadora". En Tendencias y corrientes de la historiografia mexicana del siglo XIX. Coordinado por Conrado Hernández. Zamora: El Colegio de Michoacán, 2003.

Garner, Paul. Porfirio Díaz. Del héroe al dictador, una biografía política. México D. F.: Planeta, 2003.

Gascón Mercado, Julián. Los primeros masones y la formación del Supremo Consejo de México. . México D. F.: spi, 1987.

Guerra, François-Xavier. "Lugares, formas y ritmos de la política moderna". En Boletín de la Academia Nacional de Historia 285 (enero-marzo, 1989): 7-23.

Guerra, François-Xavier. México: del Antiguo Régimen a la Revolución. México D. F.: FCE, 1992. 
Guerra, François-Xavier. Modernidad e independencias. Ensayos sobre las revoluciones hispánicas. México D. F.: FCE/ Mapfre, 1993.

Guerra, François-Xavier y Annick Lempérière coords. Los espacios públicos en Iberoamérica. Ambigüedades y problemas. Siglos XVIII-XIX. México D. F.: FCE, CFEMC, 1998.

Martínez Zaldúa, Ramón. La masonería en México. México D. F.: Publicaciones Claridad, s. f.

Mateos, José María. Historia de la masonería en México desde 1806 hasta 1884. . México D. F.: Imp. de La Tolerancia, 1884.

Navarrete, Félix (Jesús García Gutiérrez). La masonería en la historia y en las leyes de Méjico. México D. F.: Ed. Jus, 1957.

Navarrete, Félix (Jesús García Gutiérrez). De Cabarrús a Carranza. La legislación anticatólica en Méjico. México D. F.: Ed. Jus, 1957.

Pérez Rayón, Nora. "El anticlericalismo en la historia de México, una visión clerical. La acción anticatólica en México de Jesús García Gutiérrez, Pbro. e historiador, 1939”. En Horizontes y códigos culturales de la historiografía. Coordinado por Saúl Jerónimo, Danna Levin y Columba González. México D. F.: Universidad Autónoma Metropolitana - Iztapalapa, 2008.

Ramírez, Manuel Esteban. Apuntes sintéticos sobre la masonería en México durante los años de 1806 a 1921 por el Gran Luminar, gran maestro de orden del Rito Nacional Mexicano. México D. F.: Imprenta Taller linotipografía Soria, 1921.

Reyes Bravo, Alejandro. Cronología masónica. México D. F.: Ed. autor, 2000.

Rodríguez Castillejos, Manuel. La regularidad en México, y un análisis gráfico de la genealogía mexicana. México D. F.: s. p. i., 2006.

Supremo Consejo XVI, no. 93 (marzo-abril de 1986).

Tello Díaz, Carlos. Porfirio Díaz. Su vida y su tiempo. La guerra, 1830-1867. México D. F.: Conaculta, Debate, 2015.

Tenorio Trillo, Mauricio y Aurora Gómez Galvarrio. El Porfiriato. México D. F.: CIDE, FCE, 2013.

Vázquez Leos, J. Jesús. Liberalismo y masonería en San Luis. San Luis Potosí: s. p. i., 1996.

Zalce, Luis J. "Informe del muy respetable gran maestro Luis J. Zalce". En Primer Congreso Masónico Nacional. México D. F.: Ed. Secretaría del Congreso, 1925.

Zalce, Luis J. Apuntes para la historia de la masonería en México, de mis lecturas y mis recuerdos. México D. F.: Ed. del autor, dos tomos, 1950. 